\title{
The Effect of Horticulture Therapy Program for Behavior Problems and Subjective Mood and Energy of Childhood Cancer Patients
}

\author{
Yeon Ha Choi ${ }^{1,2} *$, Sang Mi Lee', Gyung Mee Gim', Seon Hee Jeong', and Sook Lee ${ }^{2,3}$ \\ ${ }^{1}$ Urban Agricultural Research Division, National Institute of Horticultural and Herbal Science, Rural Development Administration, Jeonju \\ 55365, South Korea \\ ${ }^{2}$ Department of Horticultural Therapy, Dankook University, Cheonan 31116, South Korea \\ ${ }^{3}$ Department of Nursing, Dankook University, Cheonan 31116, South Korea
}

\begin{abstract}
This study was conducted to apply a horticultural therapy program to childhood cancer patients, to analyze their psychosocial changes and thus to examine its possibility as a way to manage the recovery of childhood cancer patients. This study was conducted on patients who were diagnosed with childhood cancer, and they were divided into the experimental group (8 patients who visited $\mathrm{H}$ association offices located in 3 cities and participated in the horticultural program) and the control group (5 patients who did not participate in the program). The homogeneity between the two groups before conducting the program was compared, and there was no statistically significant difference, which proved that the two groups were homogeneous. After conducting the program, the score of social immaturity, one of the sub-categories of problem behaviors, of the experimental group was statistically significantly lower than that of the control group $(p=.019)$. Changes before and after the program within the groups were compared, and the somatization score $(p=.039)$ of the experimental group ( $p=.039)$ after the program was 1.13, down from 2.13 before the program. The social immaturity score $(p=.017)$ of the experimental group after the program was 1.00 , down from 2.63 before the program, and the attention problem score $(p=.026)$ of the group after the program was 1.25 , down from 2.50 before the program. The total problem behavior score $(p=.034)$ of the experimental group after the program was 9.63 , down from 18.50 before the program, showing a statistically significant decrease. The cumulative subjective mood score $(p=.000)$ of the experimental group throughout the entire sessions after the program was 7.82, up from 6.99 before the program, showing a statistically significant increase. Therefore, it can be concluded that the horticultural therapy program developed based on the 'relaxationsocial support-cognitive behavior' strategy was effective to reduce the negative psychosocial state of childhood cancer patients.
\end{abstract}

Keywords: cognitive behavior, psychosocial state, relaxation, social support, strategy

\section{Introduction}

In Korea, about 1,000 1,200 people are newly diagnosed with childhood cancer annually, and about 16 out of 100,000

This paper was supported by the joint research program with the Rural Development Administration (PJ01024401).

This study was supported by the academic-research cooperation program of the Rural Development Administration in 2016.

Received: December 6, 2017, Revised: December 7, 2017, Accepted: December 23, 2017

*Comesponding author: sangmilee@korea.kr 
childhood population $(0.016 \%)$ are diagnosed with cancer, which is similar to the global frequency (KAFCLC, 2012). However, as new medical technologies are developed, the survival rate of childhood cancer that was recognized as an incurable disease has significantly increased. The survival rate of acute leukemia and brain tumor is $27.8 \%$ and $22.5 \%$ respectively, and the 5-year relative survival rate of major types of childhood cancer has increased from $54.6 \%$ in 1995 to $80.5 \%$ in 2013 (NCIC, 2015). As these data show, childhood cancer starts to be recognized as a chronic disease that require a long period of treatment not as an incurable disease (Lee, 2016). Meanwhile, childhood cancer is a very shocking event to cancer patients who have to face challenges such as physical and psychological pain, painful treatment, changes and restrictions, uncertainty and a complex sense of loss, and the unique challenges and stress to childhood cancer patients delay or deter the achievement of developmental tasks (Woodgate, 2005) and also affect their emotional stability and personality (Lee, 2008). This highlights the necessity of quality programs for improving the emotional stability and sociality of childhood cancer patients (Harvey et al., 1999; Kapelaki et al., 2003; Sung et al., 2011; Yeo, 2006). Therefore, psychosocial intervention is required to reduce the negative psychological and social problems of childhood cancer patients and to improve the quality of their life.

Recently, horticultural therapy has emerged as an eco-friendly psychosocial intervention method that contributes to reducing problem behaviors observed in childhood, and improving self-esteem and sociality. In an earlier study, a horticultural therapy program that excites the five senses was provided 16 times for low-income family children in the lower grades who used local children's centers, and the program was found to have a positive impact on their concentration and self-control (Lee, 2010). In another study on a horticultural therapy program using vegetable gardening activities, 29 sessions were provided for 6-year old preschool children, and their social immaturity, and, in particular, the depression and anxiety of girls were reduced (Lee, 2005). In a study conducted on 15 children staying in an orphanage, 15 sessions of a horticultural therapy program were provided, and their sociality was improved (Moon, 2009). It was also reported that an ecological horticultural activity program composed of 12 sessions conducted in a weekend eco-school was effective to build the positive self-esteem and sociality of elementary school students (Nam, 2009). However, no study has been conducted in Korea on a horticultural therapy program for childhood cancer patients, while it was reported overseas that planting and gardening activities provided for childhood cancer patients in a pediatric ward in an university hospital was effective to improve their sensory stimulation and communication skills, as well as their hope for the future and the quality of life of patients and their families (Matthew, 2008).

Against this backdrop, this study aimed to evaluate the possibility of using horticultural therapy for childhood cancer patients as a psychosocial approach. To do so, psychosocial therapy intervention for cancer patients developed by Fawzy (1999) was modified for the recovery management of cancer patients based on the 'relaxation-social support-cognitive behavior' strategy, and its effect to reduce the negative psychosocial state of patients that they experience while struggling against cancer was examined in this study.

\section{Methods}

\section{Research design}

In this study, pre-post test design was used to examine the effect of a horticultural therapy program developed based on the 'relaxation-social support-cognitive behavior' strategy on the problem behaviors and subjective mood state of childhood cancer patients (Table 1). 
Table 1. Research design for this study.

\begin{tabular}{llcc}
\hline Group & \multicolumn{3}{c}{ Process } \\
\hline Exp. & $\mathrm{O}_{1}$ & $\mathrm{X}$ & $\mathrm{O}_{2}$ \\
Cont. & $\mathrm{O}_{1}$ & & $\mathrm{O}_{2}$ \\
\hline
\end{tabular}

$\mathrm{O}_{1}$ : Pre-test, $\mathrm{O}_{2}$ : Post-test.

$\mathrm{X}$ : Horticultural therapy program based on 'relaxation-social support-cognitive behavior' strategy focused on indoor activities.

\section{Research subjects}

In this study, a notice on this program was posted on the homepage and bulletin board of $\mathrm{H}$ association targeting childhood cancer patients who visited $\mathrm{H}$ association located in S, D and P cities, and participants were recruited through voluntary applications of parents or patients, or through recommendations from relevant persons in the association. The researcher of this study informed participants and guardians of the information related to this study, and they signed a consent form for participation in the program and the use of personal information. The selected subjects were divided into the experimental group (14 subjects who participated in the horticultural therapy program developed in this study) and the control group (8 subjects who did not participate in the program), but considering the sufficiency of the questionnaire answers and the rate of participation in the program, the results of 8 subjects in the experimental group and 5 subjects in the control group were analyzed finally. Out of the final subjects, 5 subjects were males and 8 subjects were females, and their average age was full 12 years old. The majority of the subjects (11 subjects) were diagnosed with acute lymphocytic leukemia, and one with Hodgkin lymphoma, and one with acute myelogenous leukemia.

\section{Research tools}

\section{Horticultural therapy program}

\section{(1) Assessment}

To identify the demographic characteristics of the subjects and key problems prior to conducting the program, a questionnaire survey was conducted on relevant persons in $\mathrm{H}$ association and the guardians of patients about disease, time of diagnosis, administered medication or treatment, ongoing complementary and alternative therapy and hobbies, and the survey was performed using a self-reporting method for subjects and an observer-reporting method for their main guardians. The demographic characteristics of the subjects include age, diagnosed disease, time of diagnosis, treatment type, administered medication, and complementary and alternative therapy, and key problems include problem behaviors, depression, increasing anxiety and decreasing self-esteem.

\section{(2) Planning and implementing}

Based on the information collected in the assessment phase, childhood cancer patients were diagnosed with the 'increasing negative psychosocial state caused by their life of struggling against disease' from a perspective of horticultural therapy, and the purpose of treatment was set to 'reduce the negative psychosocial state.'

Cancer patients have weak physical strength caused by chemotherapy and, in particular, patients who receive radiation treatment show an increased reaction of the skin to exposure to sunlight. Considering the characteristics of cancer patients, indoor activities were planned, and, based on the results of surveys on the preference of cancer patients (Lee et al., 2015) and elementary school students (NIHHS, 2016) for horticultural activities and plants, plants and activities that are less likely to cause an injury or infection to childhood cancer patients and that can be applied to children were selected among 
those that are high on the list. Planting activities including making a grass doll and planting herbs and succulent plants were applied and the results of such activities were utilized in the next sessions. Decorating activities include making a fragrant pouch with harvested herbs, making a flower basket with harvested flowers and making a pressed flower food mat and a dried flower corsage with the rest flowers. A garden party was planned, and simple cooking activities using vegetables and fruits and activities decorating the party space were also planned throughout the sessions.

The horticultural therapy model of the 'relaxation-social support-cognitive behavior' strategy (Lee et al., 2015; Lee et al., 2016) was developed based on the psychosocial therapeutic intervention model for cancer patients (Fawzy, 1999), which includes strategies for 'relaxation, social support, cognitive reassessment, problem solving reactions and stress management.' The model was restructured to include the strategy for relaxation and social support, and that for cognitive behaviors that encompasses the processes of 'identifying inappropriate thoughts and feelings, recognizing their own strengths, solving problems from a positive perspective, and reassessing themselves positively.'

In the model above, a quiet space that can secure independent activities and block outside noise was provided for the relaxation of patients, and activities were performed sitting on the floor to prevent a severe loss in their physical strength caused by long hours of sitting on a chair. Sitting cushions were used to prevent blood flow disorders and thus to increase comfort. In addition, since activities of concentrating on a goal result in relaxation, unnecessary interruptions and verbal intervention were avoided during activities to ensure patients focus on activities. For social support, therapists took an attitude of embracement, trust, affection, sympathy and closeness, and information on the effects of plants on health, and plants or materials were provided as much as possible in each session to provide knowledge on the status of their disease and materials and services as Fawzy (1999) suggested as a way of social support. A task was assigned for a week between sessions to ensure participants can receive social support and feedbacks from their social and personal relationships such as families and peers after finishing one session and before starting the next session. The cognitive behavior strategy mentioned above was adopted to ensure participants to achieve the followings in phases: identifying inappropriate thoughts and feelings; recognizing their own strengths; solving problems from a positive perspective; and reassessing themselves positively.

However, the results of a survey on the preference of elementary school students for horticultural activities and plants (NIHHS, 2016) showed that their preference for herb teas was low, and thus 'making a herb tea (5th session),' and 'making s pressed flower tea cup saucer (6th session)' in the horticultural therapy program developed based on the 'relaxation-social support-cognitive behavior' strategy (Lee et al., 2015; Lee et al., 2016), were replaced with 'making a herb potpourri' and 'making a pressed flower food mat' respectively. The program performed in this study is as shown in

Table 2. Horticultural therapy program based on 'relaxation-social support-cognitive behavior' strategy focused on indoor activities.

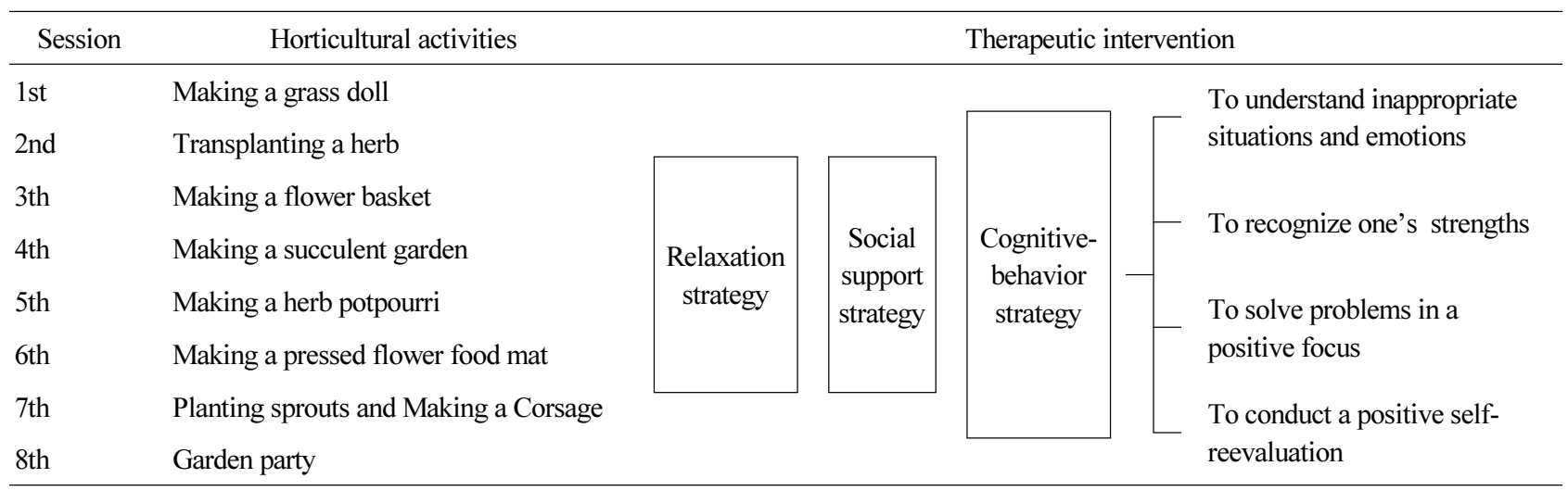


Table 2.

The $1^{\text {st }}$ program was provided for 4 patients in S center every Friday from January 4 to March 7,2016 , and the $2^{\text {nd }}$ program was provided for 4 patients in D center every Friday from April 6 to June 4, 2016. One session per week (a total of 8 sessions) was held and each session was 90 minutes long. One main therapist and 3 sub-therapists who have Horticultural Therapist Registered-Grade I or II certified by the Korean Horticultural Therapy and Wellbeing Association (KHTA) led the program.

\section{Measurement tools}

Tools used in this study to evaluate the effects of the horticultural therapy program are as the followings.

\section{Korea-Child Behavior Checklist (K-CBCL)}

The Korea-Child Behavior Checklist (K-CBCL) is used to evaluate problem behaviors of children and juveniles, and this is a form standardized by Oh et al. (1997) based on the Child Behavior Checklist (CBCL) developed by Achenbach and Edelbrock (1983). The checklist was filled by the main guardians of patients in this study two times before and after the horticultural therapy program based on what they observed from the patients. The checklist was provided for the main guardians in advance and collected it on the day when the program began. After finishing the program, the checklist was provided for the main guardians again and collected via mail. In general, the checklist is composed of two parts: social competence scale, and behavior problem scale, but in this study the behavior problem scale was used only. From the original behavior problem scale checklist, Questions 2 and 4 with which it is very difficult to distinguish between the clinical and control groups due to their very low frequency of answers, Questions 56, 57 and 58 on sexual problems that are not suitable for the target subjects of this study, and Questions 5, 59, 60, 73, 109 and 110 on emotional instability were excluded in this study, and thus a total of 110 questions were included in the checklist and the total score ranged from 0 to 220. They were divided into sub-categories as follows: 9 questions on withdrawal, 9 questions on somatization, 14 questions on depression/anxiety, 8 questions on social immaturity, 7 questions on cognitive problems, 11 questions on attention problems, 13 questions on delinquency, 20 questions on aggression, and 27 questions on others. The higher the score, the more severe the problem behaviors. Cronbach's $\alpha$ presented in the developed checklist was 0.68 , and that in this study was 0.85 .

\section{Subjective mood and energy state}

The subjective mood and energy state of patients were measured using the Affect Grid developed by Russell et al. (1989), which is a single-item scale. The Affect Grid is a mood scale that requires respondents to place a mark on a two-dimensional $9 \times 9$ grid to indicate their current mood and arousal, and it is an indicator to measure the emotional or affective arousal state of a respondent that is not permanently lasting but changing over the period. With the Affect Grid, the subjective mood of a person can be measured in a repetitive, easy and simple way. The horizontal axis represents variations in unpleasant and pleasant feelings from the left (1 point) to the right ( 9 points), and the vertical axis represents variations in sleepiness and arousal states from the bottom (1 point) to the top ( 9 points). The Affect Grid in this study was checked by respondents themselves before and after each session, a total of 16 times. They can identify their mood with the score that the scores on the horizontal and vertical axes, and the 45 degree positive and negative directions on the grid mean depression vs arousal, and stress vs stability respectively. The mood and arousal states of a respondent can be measured separately according to the purpose or needs of a study. A respondent can measure his or her current mood and 
changes in the mood themselves relatively easily and simply. With the Affect Grid, repetitive mood conditions with a certain interval can be measured, and the grid is widely used to measure subjective mood conditions before and after conducting an experiment. Its reliability is known to range from 0.81 to 0.91 .

\section{Analysis methods}

The collected data were processed using SPSS Win 23.0. The homogeneity between the control group and the experimental group before conducting this experiment, and differences between the two groups after conducting this experiment were analyzed and verified using the Mann-Whitney U-test, and the pre-post comparison within the groups was analyzed and verified using the Wilcoxon signed rank test.

\section{Limitations in the study}

The number of samples applied to the program in this study was small, and this experiment was conducted in limited areas targeting those who voluntarily applied for the test only, which resulted in inhomogeneous conditions such as the diagnosed diseases, time of diagnosis and gender of subjects in the control and experimental groups. In addition, since the application of other therapeutic methods that can affect the psychosocial state of the experimental group was not controlled, it is difficult to generalize the results of this study.

\section{Results and Discussion}

\section{Homogeneity test prior to the test}

\section{Problem behaviors}

The homogeneity of problem behaviors between the control and experimental groups before conducting the horticultural therapy program was as shown in Table 3. The average score of the experimental and control groups was 18.13 and 21.40

Table 3. Homogeneity test of problem behaviors between experimental and control groups before horticultural therapy program.

\begin{tabular}{|c|c|c|c|c|c|}
\hline & Item & $\mathrm{E}(\mathrm{N}=8)$ & $\mathrm{C}(\mathrm{N}=5)$ & $\mathrm{Z}$ & $p$ \\
\hline \multirow{11}{*}{$\begin{array}{l}\text { Problem } \\
\text { behavior }\end{array}$} & Withdrawn & $1.50 \pm 1.20^{z}$ & $1.60 \pm 1.14$ & -0.151 & $0.880^{\mathrm{NS}}$ \\
\hline & Somatization & $2.13 \pm 2.80$ & $2.20 \pm 3.27$ & -0.153 & $0.878^{\mathrm{NS}}$ \\
\hline & Depression/Anxiety & $3.13 \pm 3.72$ & $3.20 \pm 1.64$ & -0.594 & $0.553^{\mathrm{NS}}$ \\
\hline & Social immature & $2.63 \pm 2.45$ & $3.20 \pm 1.10$ & -1.081 & $0.280^{\mathrm{NS}}$ \\
\hline & Cognitive problem & $0.38 \pm 0.74$ & $0.60 \pm 0.55$ & -0.935 & $0.350^{\mathrm{NS}}$ \\
\hline & Attention problem & $2.50 \pm 2.00$ & $2.80 \pm 1.92$ & -0.239 & $0.811^{\mathrm{NS}}$ \\
\hline & Delinquent Behavior & $0.38 \pm 0.52$ & $0.40 \pm 0.55$ & -0.087 & $0.931^{\mathrm{NS}}$ \\
\hline & Aggression & $5.13 \pm 3.80$ & $4.60 \pm 2.30$ & -0.224 & $0.823^{\mathrm{NS}}$ \\
\hline & Internalizing problems & $6.63 \pm 5.66$ & $7.00 \pm 4.58$ & -0.368 & $0.713^{\mathrm{NS}}$ \\
\hline & Externalizing problems & $5.50 \pm 3.85$ & $5.00 \pm 2.55$ & -0.074 & $0.941^{\mathrm{NS}}$ \\
\hline & Total score & $18.13 \pm 12.51$ & $21.40 \pm 10.99$ & -0.587 & $0.557^{\mathrm{NS}}$ \\
\hline
\end{tabular}

$\mathrm{E}=$ Experiment group; $\mathrm{C}=$ Control group.

${ }^{\mathrm{z}}$ Mean \pm Standard deviation.

${ }^{\mathrm{NS}}$ Nonsignificant leveled by Mann-Whitney U-test. 
respectively, showing no statistically significant difference ( $p=.557)$, and there was no statistically significant result in all the sub-categories, which proves that the two groups are homogeneous.

\section{Comparison of mean values between the groups after the horticultural therapy program}

\section{Problem behavior}

The problem behavior scores of the experimental and control groups after conducting the horticultural therapy program were compared as shown in Table 4. Among the sub-categories, the score of social immaturity of the experimental and control groups was 1.00 and 3.80 respectively, which indicates that the score of the experimental group was statistically significantly lower than that of the control group $(p=.019)$.

\section{Comparison of pre-post mean values within the groups}

\section{Problem behavior}

\section{(1) Experimental group}

Changes in the problem behaviors of childhood cancer patients after the horticultural therapy program are as shown in Table 5. The somatization score before and after the program was 2.13 and 1.13 respectively $(p=.039)$, and the social immaturity score before and after the program was 2.63 and 1.00 respectively $(p=.017)$. The attention problem score before and after the program was 2.50 and 1.25 respectively $(p=.026)$. The total problem behavior score before and after the program was 18.13 and 9.63 respectively ( $p=.034)$, indicating that the score was statistically significantly reduced after the program.

\section{(2) Control group}

Changes in the problem behaviors of childhood cancer patients who did not participate in the horticultural therapy

Table 4. Difference comparison of problem behaviors between experimental and control groups after horticultural therapy program.

\begin{tabular}{cccccc}
\hline & Item & $\mathrm{E}(\mathrm{N}=8)$ & $\mathrm{C}(\mathrm{N}=5)$ & $\mathrm{Z}$ & $p$ \\
\hline Withdrawn & $0.63 \pm 0.74^{\mathrm{z}}$ & $1.00 \pm 1.00$ & -0.708 & $0.479^{\mathrm{NS}}$ \\
Somatization & $1.13 \pm 2.42$ & $2.20 \pm 1.79$ & -1.474 & $0.140^{\mathrm{NS}}$ \\
& $1.50 \pm 1.51$ & $3.00 \pm 2.12$ & -1.338 & $0.181^{\mathrm{NS}}$ \\
Pepression/Anxiety & $1.00 \pm 1.77$ & $3.80 \pm 1.92$ & -2.341 & $0.019^{*}$ \\
behavior & Social immature & $0.50 \pm 0.76$ & $0.60 \pm 0.89$ & -0.168 & $0.866^{\mathrm{NS}}$ \\
& Cognitive problem & $1.25 \pm 1.39$ & $2.40 \pm 1.82$ & -1.282 & $0.200^{\mathrm{NS}}$ \\
& Attention problem & $1.38 \pm 1.69$ & $0.40 \pm 0.55$ & -1.175 & $0.240^{\mathrm{NS}}$ \\
& Delinquent Behavior & $2.75 \pm 3.24$ & $3.20 \pm 1.92$ & -0.742 & $0.458^{\mathrm{NS}}$ \\
& Aggression & $3.25 \pm 4.30$ & $6.00 \pm 3.32$ & -1.700 & $0.089^{\mathrm{NS}}$ \\
& Internalizing problems & $4.13 \pm 4.58$ & $3.60 \pm 2.07$ & -0.074 & $0.941^{\mathrm{NS}}$ \\
& Externalizing problems & $9.63 \pm 10.16$ & $17.80 \pm 10.40$ & -1.541 & $0.123^{\mathrm{NS}}$ \\
\hline
\end{tabular}

$\mathrm{E}=$ Experiment group; $\mathrm{C}=$ Control group.

${ }^{\mathrm{z}}$ Mean \pm Standard deviation.

${ }^{\mathrm{NS}}$ Nonsignificant, ${ }^{*} p<.05$ leveled by Mann-Whitney U-test. 
Table 5. Pre-post mean comparison for problem behaviors for within groups of horticultural therapy program.

\begin{tabular}{|c|c|c|c|c|}
\hline Item & & Pre-HT & Post-HT & $p$ \\
\hline \multirow{2}{*}{ Withdrawn } & $\mathrm{E}(\mathrm{N}=8)$ & $1.50 \pm 1.20^{\mathrm{z}}$ & $0.63 \pm 0.74$ & $0.102^{\mathrm{NS}}$ \\
\hline & $\mathrm{C}(\mathrm{N}=5)$ & $1.60 \pm 1.14$ & $1.00 \pm 1.00$ & $0.257^{\mathrm{NS}}$ \\
\hline \multirow{2}{*}{ Somatization } & $\mathrm{E}$ & $2.13 \pm 2.80$ & $1.13 \pm 2.42$ & $0.039^{*}$ \\
\hline & $\mathrm{C}$ & $2.20 \pm 3.27$ & $2.20 \pm 1.79$ & $1.000^{\mathrm{NS}}$ \\
\hline \multirow{2}{*}{ Depression/Anxiety } & $\mathrm{E}$ & $3.13 \pm 3.72$ & $1.50 \pm 1.51$ & $0.288^{\mathrm{NS}}$ \\
\hline & $\mathrm{C}$ & $3.20 \pm 1.64$ & $3.00 \pm 2.12$ & $0.705^{\mathrm{NS}}$ \\
\hline \multirow{2}{*}{ Social immature } & $\mathrm{E}$ & $2.63 \pm 2.45$ & $1.00 \pm 1.77$ & $0.017^{*}$ \\
\hline & $\mathrm{C}$ & $3.20 \pm 1.10$ & $3.80 \pm 1.92$ & $0.257^{\mathrm{NS}}$ \\
\hline \multirow{2}{*}{ Cognitive problem } & $\mathrm{E}$ & $0.38 \pm 0.74$ & $0.50 \pm 0.76$ & $0.317^{\mathrm{NS}}$ \\
\hline & $\mathrm{C}$ & $0.60 \pm 0.55$ & $0.60 \pm 0.89$ & $1.000^{\mathrm{NS}}$ \\
\hline \multirow{2}{*}{ Attention problem } & $\mathrm{E}$ & $2.50 \pm 2.00$ & $1.25 \pm 1.39$ & $0.026^{*}$ \\
\hline & $\mathrm{C}$ & $2.80 \pm 1.92$ & $2.40 \pm 1.82$ & $0.785^{\mathrm{NS}}$ \\
\hline \multirow{2}{*}{ Delinquent Behavior } & $\mathrm{E}$ & $0.38 \pm 0.52$ & $1.38 \pm 1.69$ & $0.066^{\mathrm{NS}}$ \\
\hline & $\mathrm{C}$ & $0.40 \pm 0.55$ & $0.40 \pm 0.55$ & $1.000^{\mathrm{NS}}$ \\
\hline \multirow{2}{*}{ Aggression } & $\mathrm{E}$ & $5.13 \pm 3.80$ & $2.75 \pm 3.24$ & $0.092^{\mathrm{NS}}$ \\
\hline & $\mathrm{C}$ & $4.60 \pm 2.30$ & $3.20 \pm 1.92$ & $0.102^{\mathrm{NS}}$ \\
\hline \multirow{2}{*}{ Internalizing problems } & $\mathrm{E}$ & $6.63 \pm 5.66$ & $3.25 \pm 4.30$ & $0.058^{\mathrm{NS}}$ \\
\hline & $\mathrm{C}$ & $7.00 \pm 4.58$ & $6.00 \pm 3.32$ & $0.684^{\mathrm{NS}}$ \\
\hline \multirow{2}{*}{ Externalizing problems } & $\mathrm{E}$ & $5.50 \pm 3.85$ & $4.13 \pm 4.58$ & $0.673^{\mathrm{NS}}$ \\
\hline & $\mathrm{C}$ & $5.00 \pm 2.55$ & $3.60 \pm 2.07$ & $0.102^{\mathrm{NS}}$ \\
\hline \multirow{2}{*}{ Total score } & $\mathrm{E}$ & $18.13 \pm 12.51$ & $9.63 \pm 10.16$ & $0.034^{*}$ \\
\hline & $\mathrm{C}$ & $21.40 \pm 10.99$ & $17.80 \pm 10.40$ & $0.588^{\mathrm{NS}}$ \\
\hline
\end{tabular}

$\mathrm{E}=$ Experiment group; $\mathrm{C}=$ Control group; Pre-HT=pre horticultural therapy; Post-HT=post horticultural therapy.

${ }^{\mathrm{z}}$ Mean \pm Standard deviation.

${ }^{\mathrm{NS}}$ Nonsignificant, ${ }^{*}<.05$ leveled by Wilcoxon signed rank test.

program are as shown in Table 5. The mean value before and after the program was 21.40 and 17.80 respectively, but there was no statistically significant difference $(p=.588)$. There was no statistically significant result in all the sub-categories.

The effects of horticultural therapy based on the 'relaxation-social support-cognitive behavior' strategy on the problem behaviors of childhood cancer patients were analyzed, and the social immaturity, attention problem and total problem behavior scores of the experimental group showed a statistically significant decrease after conducting the horticultural therapy program. The social immaturity score of the experimental program was lower than that of the control group of patients who did not participate in the program, which indicates that horticultural therapy is effective to reduce the problem behaviors of childhood cancer patients. The results is attributable to the fact that participants were ensured to recognize their own thoughts and feelings and actively respond to them by intervening with the cognitive behavior strategy through various horticultural activities. It was also reported that childhood cancer patients who were able to actively respond to problem solving showed lower scores in the level of stress, less internalizing and externalizing 
problems, and higher scores in psychosocial adaptation (Trask et al., 2003), and in another earlier study, it was found that cognitive behavior therapy positively improved the self-perception of withdrawn children (Baek, 2006). These results coincide with those of this study. In addition, after completing activities, a task was assigned between sessions to improve the existing social relationships of patients, and they were encouraged to positively perform the task. When they presented the results of their task, therapists and peers listened to their presentation attentively and showed positive reactions. These follow-up activities seem to contribute to the positive results of this study. In the study of Feiring and Lewis(1991), the leadership of pro-social behaviors was significantly improved by peer support. During childhood and adolescence, children and adolescents build and express their thoughts, but childhood cancer patients are excluded from decision making and are overly protected by parents in the treatment process. Thus, they are unable to achieve social developmental tasks smoothly. Horticultural therapy activities, however, provide them with chances to build and talk about their own thoughts and to experience positive reactions to their thoughts in social relationships, which seemed to reduce the social immaturity of childhood cancer patients. In addition, the attention problems of the experimental group were reduced in this study. Looking at blue and green colors increases the alpha wave and relaxation and improves indicators related to attention and cerebral activities (Lee, 2014), and considering the finding, green-colored plants provided for horticultural activities seemed to relax the tension of childhood cancer patients and improve their attention. The attention of children also is improved when doing horticultural activities such as cutting, sticking, bending and making (Lee, 2010), and activities adopted in this study such as arranging flowers, making a flower potpourri, a pressed flower food mat and a corsage required activities that use plants actively such as cutting, sticking, bending and making, which seemed to reduce the attention problems of childhood cancer patients.

\section{Subjective mood state}

a. Subjective mood state by session

Changes in the subjective mood state of childhood cancer patients after conducting the horticultural therapy program were measured as shown in Table 6. In every session, the score after the program was increased from the score before the program. In the $1^{\text {st }}$ session, the score was increased from 7.00 before the program to 8.10 after the program ( $\left.p=.035\right)$, and in the $4^{\text {th }}$ session, the score was increased from 5.50 to 7.83 , showing a statistically significant increase $(p=.039)$.

Table 6. Pre-post mean comparison for subjective mood state within experimental group of each session.

\begin{tabular}{ccccc}
\hline Mood & Session & Pre-HT & Post-HT & $p$ \\
\hline & 1th & $7.00 \pm 1.78^{\mathrm{z}}$ & $8.10 \pm 0.52$ & $0.035^{*}$ \\
& 2th & $6.67 \pm 1.83$ & $7.33 \pm 1.17$ & $0.194^{\text {NS }}$ \\
E $(\mathrm{N}=8)$ & $7.61 \pm 1.17$ & $8.50 \pm 0.00$ & $0.317^{\text {NS }}$ \\
& 3th & $5.50 \pm 2.45$ & $7.83 \pm 0.82$ & $0.039^{*}$ \\
& 4th & $6.88 \pm 1.30$ & $7.69 \pm 1.13$ & $0.268^{\text {NS }}$ \\
& 5th & $7.00 \pm 1.41$ & $7.50 \pm 2.45$ & $0.279^{\text {NS }}$ \\
& 6th & $7.17 \pm 2.24$ & $7.61 \pm 1.27$ & $0.257^{\text {NS }}$ \\
\hline
\end{tabular}

E=Experiment group; Pre-HT=pre horticultural therapy; Post-HT=post horticultural therapy.

${ }^{\mathrm{z}}$ Mean \pm Standard deviation.

${ }^{\mathrm{NS}}$ Nonsignificant, ${ }^{*} p<.05$ leveled by Wilcoxon signed rank test. 
b. Cumulative subjective mood state score throughout the entire sessions

The cumulative subjective mood state scores before and after the program were compared as shown in Table 7. The cumulative score after the program was 7.82, up from 6.99 before the program, showing a statistically significant increase $(p=.000)$.

\section{(3) Subjective energy state}

a. Subjective energy state by session

Changes in the subjective energy state of childhood cancer patients after conducting the horticultural therapy program were measured as shown in Table 8. In every session, the score after the program was increased from the score before the program, but there was no statistically significant difference.

b. Cumulative subjective energy state score throughout the entire sessions

The cumulative subjective energy state scores before and after the program were compared as shown in Table 9. The

Table 7. Pre-post mean comparison for subjective mood state within experimental group of total session cumulative score.

\begin{tabular}{|c|c|c|c|}
\hline Mood & Pre-HT & Post-HT & $p$ \\
\hline $\mathrm{E}(\mathrm{N}=57)$ & $6.99 \pm 1.71^{\mathrm{z}}$ & $7.82 \pm 1.23$ & $0.000^{* * *}$ \\
\hline
\end{tabular}

$\mathrm{E}=$ Experimental group; Pre-HT=pre horticultural therapy; Post-HT=post horticultural therapy.

${ }^{\mathrm{z}}$ Mean \pm Standard deviation.

${ }^{* * *}<.001$ leveled by Wilcoxon signed rank test.

Table 8. Pre-post mean comparison for subjective energy state within experimental group of each session.

\begin{tabular}{ccccc}
\hline Energy & Session & Pre-HT & Post-HT & $p$ \\
\hline \multirow{6}{*}{ 1th } & $6.60 \pm 1.91^{\mathrm{z}}$ & $7.40 \pm 1.45$ & $0.071^{\mathrm{NS}}$ \\
& 2 th & $5.50 \pm 2.53$ & $6.83 \pm 1.37$ & $0.131^{\mathrm{NS}}$ \\
$\mathrm{E}(\mathrm{N}=8)$ & $7.56 \pm 1.29$ & $6.00 \pm 3.51$ & $0.180^{\mathrm{NS}}$ \\
& 4 th & $5.70 \pm 2.28$ & $6.67 \pm 2.14$ & $0.197^{\mathrm{NS}}$ \\
& 5 th & $6.50 \pm 1.41$ & $7.06 \pm 1.50$ & $0.340^{\mathrm{NS}}$ \\
& 6 th & $6.88 \pm 2.07$ & $6.88 \pm 2.45$ & $1.000^{\mathrm{NS}}$ \\
& 7 th & $7.28 \pm 1.39$ & $7.61 \pm 1.17$ & $0.180^{\mathrm{NS}}$ \\
& 8th & $7.10 \pm 0.89$ & $7.63 \pm 1.46$ & $0.577^{\mathrm{NS}}$ \\
\hline
\end{tabular}

$\mathrm{E}=$ Experimental group; Pre-HT=pre horticultural therapy; Post-HT=post horticultural therapy

${ }^{\mathrm{z}}$ Mean \pm Standard deviation.

${ }^{\mathrm{NS}}$ Nonsignificant leveled by Wilcoxon signed rank test

Table 9. Pre-post mean comparison for subjective energy state within experimental group of total session cumulative score.

\begin{tabular}{lccc}
\hline Energy & Pre-HT & Post-HT & $p$ \\
\hline $\mathrm{E}(\mathrm{N}=57)$ & $6.69 \pm 1.82^{\mathrm{z}}$ & $7.11 \pm 1.86$ & $.037^{*}$ \\
\hline
\end{tabular}

E=Experimental group; Pre-HT=pre horticultural therapy; Post-HT=post horticultural therapy.

${ }^{\mathrm{z}}$ Mean \pm Standard deviation.

${ }^{*} p<.05$ leveled by Wilcoxon signed rank test. 
cumulative score after the program was 7.11, up from 6.69 before the program, showing a statistically significant increase $(p=.037)$.

The effects of 'relaxation-social support-cognitive behavior' horticultural therapy on the subjective mood of childhood cancer patients were examined. The experimental group of patients who participated in the horticultural therapy program showed a statistically significant improvement in their subjective mood after the program compared to that before the program, which indicates that horticultural therapy is effective to improve the subjective mood of childhood cancer patients. Participants expressed their satisfaction to the outcome of activities in each session, and named their work using positive expressions such as 'hope,' 'dream,' and 'joy.' Through horticultural activities, they recognized themselves positively and their satisfaction from their daily life was also improved, which accelerated positive thinking and behaviors in daily life (Kim, 2014). In addition, they were able to have a sense of achievement through the outcomes of horticultural activities, and to have a vicarious experience by watching their peers successfully finishing activities (Cheung, 2010). Evaluations and encouragement from people around them seemed to increase their expectations on the outcomes of activities, which, in turn, seemed to result in the arousal state and serve as a positive trigger.

\section{Conclusions}

This study was conducted to apply a horticultural therapy program to childhood cancer patients, to analyze their psychosocial changes and thus to examine its possibility as a way to manage the recovery of childhood cancer patients. As a result, after conducting the program, the score of social immaturity, one of the sub-categories of problem behaviors, of the experimental group was statistically significantly lower than that of the control group. In addition, scores before and after the horticultural therapy program were compared, and the scores of sub-categories of the problem behavior category including somatization, social immaturity and attention problem, and the total problem behavior of the experimental group was statistically significantly reduced, and the subjective mood state was improved.

These results indicated that the horticultural therapy program developed based on the 'relaxation-social supportcognitive behavior' strategy was effective to reduce the negative psychosocial state of childhood cancer patients. Therefore, horticultural therapy based on the 'relaxation-social support-cognitive behavior' strategy can be applied as an approach to reduce the psychosocial problems of childhood cancer patients.

\section{References}

Achenbach, T.M. and C.S. Edelbrock. 1983. Manual for the child behavior checklist and profile. Burlington, USA: University of Vermont.

Baek, S.I. 2006. Effects of play-based cognitive restructuring program on the children's self perception in broken families. MS thesis. Daegu univ., Daegu, Korea.

Cheung, E.S. 2010. Effect of therapeutic horticultural activities on the reduction of self-efficacy in virtual space and the prevention of internet addiction of middle school students. MS Thesis. Konkuk Univ., Seoul. Korea.

Fawzy, F.I. 1999. Psychosocial Interventions for Patients with Cancer : What Works and What Doesn't. European Journal of Cancer, 35(11):1559-1564.

Feiring, C. and M. Lewis. 1991. The transition from middle childhood to early adolescence : Sex differences in the social network and perceived self-competence. Sex Roles 24(7):489-506.

Harvey, J., Hobbie, W.L., Shaw, S., and S. Bottomley. 1999. Providing quality care in childhood cancer survivorship : Learning from the past, looking to the future. J. Pediatr. Oncol. Nurs. 16(3):117-125. DOI: 10.1016/S1043-4542(99) 
90009-7

Kapelaki, U., Fovakis, H., Dimitriou, H., Perdikogianni, C., Stiakaki, E., and M. Kalmanti. 2003. A novel idea for an organized hospital/school program for children with malignancies : Issue in implementation. Pediatric Hematology and Oncology 20(2):79-87. DOI: 10.1080/0880010390158586

Kim, K.M. 2014. The effect of gardening on positive thinking and use of words for elementary students. MS Thesis. Seoul National Univ. of Education, Seoul, Korea.

KAFCLC (Korean Association For Children with Leukemia and Cancer), 2012. Everything you need to know about childhood cancer 1 : Complete conquest with basic 80 questions and answers about childhood cancer. Seoul, Korea: Korean Association For Children with Leukemia and Cancer. Retrieved from http://www.soaam.or.kr/board/ view.php?code $=$ pds\&cat $=2 \&$ sq $=4001 \&$ page $=1 \&$ s_fld $=\&$ s_txt $=\% \mathrm{~EB} \% \mathrm{AA} \% \mathrm{~A} \% \mathrm{~EB} \% 93 \% \mathrm{~A} 0+\% \mathrm{EA} \% \mathrm{~B} 2 \% 83$

Lee, J. 2016. Art therapy single case study of a patient with infant-adolescent cancer. MS Thesis. Ewha Womans Univ., Seoul, Korea.

Lee, M.H. 2005. Effects of horticultural activities on problem behaviors and functions of kindergarten children. MS Thesis. Dankook Univ., Seoul, Korea.

Lee, P. 2010. Effects of five sense-stimulation horticultural therapy on the attention concentration and juvenile delinquency in children with low-income families. MS Thesis. Kyungpook national Univ., Sangju, Korea.

Lee, H.W. 2014. A study on characteristics of eeg changes in adolescents'attention concentration by color stimulation. MS Thesis. Chungnam Natl. Univ., Daejon, Korea.

Lee, S.M., Choi, Y.H., Gim, G.M., Jeong, S.H., Chun, M.S., and S. Lee. 2016. Effects of horticultural therapy program based on 'relaxation-social support-cognitive behavior' strategy on quality of life, stress and serotonin of woman cancer patients - focused on indoor activities -. J. Korean Soc. People Plants Environ. 19(4):277-284. DOI: 10.11628/ ksppe.2016.19.4.277

Lee, S.M., Gim, G.M., Jeong, S.H., Choi, Y.H., and S.O. Park. 2015, May. Preference about horticultural activities and plants for horticultural therapy program development in cancer patients. Paper presented at the 102th Spring Conference on Korea Society for Horticultural Science, Jeonju, Korea.

Lee, Y.Z. 2008. The effects of school re-entry support program in the hospital school on the self-perception of children with cancer. MS Thesis. Ewha Womans Univ., Seoul. Korea.

Matthew, W. 2008. Horticultural therapy : A psychosocial treatment option at the stephen d. hassenfeld children's center for cancer and blood disorders. Prim. Psychiatry 15(7):73-77.

Moon, H.S. 2009. Effects of horticulture therapy on the sociability and self-esteem of institutionalized children. MS Thesis. Wonkwang Univ., Iksan. Korea.

Nam, J.E. 2009. Effect of the ecological horticultural activity program of the nature school on elementrary school student's self-esteem and sociability. MS Thesis. Korea Univ., Seoul. Korea.

NCIC (National Cancer Information Center). 2015 Annual report of cancer statistic : Trends in 5-year relative survival of patients with major childhood cancer 1993-2012. Goyang, Korea: National Cancer Information Center. Retrieved from https://www.cancer.go.kr/lay1/bbs/S1T674C680/B/26/list.do?rows=12\&cpage=1\&cat=\&article_seq=\&thumb_type=\& condition $=\mathrm{A}$. TITLE\&keyword $=\% \mathrm{EC} \% 97 \% \mathrm{~B} 0 \% \mathrm{~EB} \% \mathrm{~A} 1 \% 80$

NIHHS (National Institute of Horticultural and Herbal Science). 2016. Actually lily II : Urban agriculture program manual to promote empathy and consideration. Wanju, Korea: National Institute of Horticultural and Herbal Science. Retrieved from http://203.241.55.164/ezpdf/customLayoutNew3.jsp?contentId=2F2F493A2F2F646C5F696D6167652F494D472 F36302F2F3030303030303239353538312F534552564943452F3030303030303239353538315F30312E504446

Oh, K.J., Lee, H.R., Hong, K.E., and E.H. Ha. 1997. KCBCL : Parent-adolescent agreement in the assessment of behavior problems of adolescents. Retrieved from http://www.cyber-test.co.kr.

Russell, J.A., Weiss, A., and G.A. Mendelsohn. 1989. Affect Grid : A single-item scale of pleasure and arousal. J. Personal. Soc. Psychol. 57(3):493-502. 
Sung, L., Yanofsky, R., Klaassen, R.J., Dix, D., Pritchard, S., Winick, N., Alexander S. and A. Klassen. 2011. Quality of life during active treatment for pediatric acute lymphoblastic leukemia. Int. J. Cancer 128(5):1213-1220. DOI: 10.1002/ ijc. 25433

Trask, P.C., Paterson, A.G., Trask, C.L., Bares, C.B., Birt, J., and C. Maan. 2003. Parent and adolescent adjustment to pediatric cancer : Associations with coping, social support, and family function. J. Paediatr. Oncol. Nurs. 20(1):36-47. DOI: 10.1053 jpon.2003.5

Yeo, J.Y. 2006. The psychosocial needs of children with cancer. MS Thesis, Hanyang Univ., Seoul. Korea.

Woodgate, R. L. 2005. A Different Way of Being: Adolescents Experiences with Cancer. Cancer Nurs. 28(1):8-15. 